\title{
Effect of Angiotensin II Receptor Blocker on Plasma Levels of TGF- $\beta 1$ and Interstitial Fibrosis in Hypertensive Kidney Transplant Patients
}

\author{
Amgad E. El-Agroudy Nabil A. Hassan Mohamed A. Foda Amani M. Ismail \\ Essam A. El-Sawy Omar Mousa Mohamed A. Ghoneim \\ Urology and Nephrology Center, Mansoura University, Mansoura, Egypt
}

\section{Key Words}

Transforming growth factor- $\beta 1$ - Transplantation •

Nephropathy

\begin{abstract}
Background/Aim: Transforming growth factor- $\beta 1$ (TGF$\beta 1$ ) is involved in the pathogenesis of chronic allograft nephropathy after kidney transplantation. The aim of the study was to evaluate the effect of the angiotensin receptor blocker losartan on TGF- $\beta 1$ plasma levels and proteinuria in hypertensive transplant recipients. Methods: A total of 162 transplant recipients were included in the study. The patients were randomized into 3 groups: group 1 received losartan; group II received an angiotensin-converting enzyme inhibitor (captopril), and group III received a calcium channel blocker (amlodipine). All the parameters were recorded at the time of therapy initiation and at 1, 4 and 12 weeks and 12 months thereafter. Graft biopsy before the start and at the end of the study was done to evaluate histopathological progression. $\boldsymbol{R e}$ sults: Blood pressure was controlled in the 3 groups; however, the need for other antihypertensive agents was significant in groups I and II. Treatment with losartan significantly decreased the plasma level of TGF- $\beta 1$, 24-hour urinary protein and serum uric acid $(p<0.05)$. No signifi-
\end{abstract}

\section{KARGER}

Fax +41613061234

E-Mail karger@karger.ch

www.karger.com
(C) 2003 S. Karger AG, Basel

0250-8095/03/0235-0300\$19.50/0

Accessible online at:

www. karger.com/ajn cant changes were seen in the hemoglobin or serum potassium levels. The rate of histopathological progression was significantly lower in the losartan group. No patient was discharged from the study due to side effects. Conclusions: After transplantation all drugs were able to control blood pressure with good safety and tolerability. The study demonstrates that ARB significantly decreases the plasma levels of TGF- $\beta 1$, proteinuria and uric acid. These results could play an important and decisive role in the treatment and prevention of chronic allograft nephropathy.

Copyright $@ 2003$ S. Karger AG, Basel

\section{Introduction}

Hypertension is a common problem in renal transplant recipients, its prevalence ranges from 60 to $85 \%$ in successfully transplanted recipients who were treated with calcineurin inhibitors [1]. Hypertension has been shown to correlate with increased mortality and morbidity [2], as well as with graft loss [3]. Optimum management of posttransplant hypertension remains to be defined. Calcium channel blockers (CCBs) have proven to be effective in ameliorating cyclosporine-associated nephrotoxicity, controlling hypertension and preventing post-transplant
Dr. Amgad E. El-Agroudy

Urology and Nephrology Center, Mansoura University

Mansoura (Egypt)

Tel. +20502262222, Fax +20502263717

E-Mail amgadelbaz@ahram0505.net 
acute tubular necrosis [4]. It has been proposed that the effect of angiotensin-converting enzyme (ACE) inhibitors (ACEIs) and angiotensin II (AngII) receptor blockers (ARBs) on renal hemodynamics may prevent the progression of renal glomerulosclerosis and chronic deterioration of renal function $[5,6]$.

Cyclosporine A (CsA) therapy is a major factor in the development of hypertension after renal transplantation. It also causes overexpression of AngII [7], which increases the synthesis of transforming growth factor- $\beta$ (TGF- $\beta 1$ ) [8], presumably involved in the development and progression of chronic allograft nephropathy (CAN) through induction of interstitial fibrosis, glomerulosclerosis and arterial proliferation $[9,10]$. Suthanthiran et al. [11] suggested the relationship between serum levels of TGF- $\beta 1$ and the predisposition to renal disease among the block population. The production of TGF- $\beta 1$ may be modulated by the intrarenal renin-angiotensin system, as AngII induces TGF- $\beta 1$ production and secretion by mesangial cells, and by a direct effect of CsA on the synthesis and expression of TGF- $\beta 1$ [12]. ACEIs and ARBs were demonstrated to antagonize TGF- $\beta 1$ expression [13]. Moreover, in an experimental model Amuchastegui et al. [14] demonstrated that ARBs are clearly better than CCBs in protecting against CAN. In contrast to other antihypertensive drugs, ACEIs and ARBs lower both systemic and intraglomerular pressure, which is translated into a decrease in glomerular hypertension, a reduction in proteinuria and an increase in renal functional reserve [15].

The aim of the present study was to study the effects of ARBs on blood pressure control, proteinuria, TGF- $\beta 1$ plasma level, and progression of graft function in a prospective randomized study of hypertensive renal transplant recipients.

\section{Patients and Methods}

One hundred and sixty-two first live-donor renal transplant patients with arterial hypertension were the subject of this study. All patients were at least 18 years of age and had no suspected or documented renal artery stenosis. All patients received CsA as one of the immunosuppressive drugs. The inclusion criteria were: (1) serum creatinine $\leq 2.5 \mathrm{mg} / \mathrm{dl}$, and (2) mild to moderate arterial hypertension (systolic blood pressure $>140<170$; diastolic blood pressure $>85<100 \mathrm{~mm} \mathrm{Hg}$ ) in two or more readings performed at least 3 days apart. None of the patients had previously been on ARBs or were concurrently being treated with more than two antihypertensive drugs. Chronic allograft rejection was diagnosed at the start of the study in 47 patients $(21,16$ and 10 patients in groups I, II, and III, respectively).

\section{Study Design}

The study was a controlled randomized study. Prior to the basal point, a washout of 2 weeks was required for all patients, and all antihypertensive medication was withdrawn. All the patients were randomized into 3 treatment groups: group I received ARBs (losar$\tan$ ) at a dose of $50 \mathrm{mg} /$ day; group II received an ACEI (captopril) at a dose of $25 \mathrm{mg} /$ day, and group III received a CCB (amlodipine) at a dose of $5 \mathrm{mg}$ /day. Groups II and III served as controls. Immunosuppressive therapy was not modified during the study period. Blood pressure was adjusted during the study to values of $<130 / 80 \mathrm{~mm} \mathrm{Hg}$, introducing doxazosin, prazosin, atenolol or frusimide when necessary. All the patients provided written informed consent.

\section{Study Variables}

All patients were followed up regularly in the outpatient clinic. Parameters were measured initially at the basal time before introduction of the drugs and then at 1,4 , and 12 weeks until the end point after 12 months. At every point in the study, the following determinations were made.

Arterial blood pressure was measured by mercury manometer after 5 min of sitting. The first and fifth Korotkoff sounds were used as indications for systolic and diastolic blood pressure.

The biochemical and hematological parameters including hemoglobin and hematocrit, serum creatinine, sodium, potassium and uric acid concentrations, were measured by conventional laboratory techniques. Proteinuria was measured in 24-hour urine samples.

Whole blood trough CsA levels were measured by a fluorescence polarization assay (Abbott Diagnostic Laboratories, Abbott Park, Ill., USA), and CsA dose was adjusted to keep the CsA level between 75 and $125 \mathrm{ng} / \mathrm{ml}$.

TGF- $\beta 1$ plasma levels were measured by the $\mathrm{E}_{\max }$ Immunoassay System (Promega Corp., Madison, Wisc., USA). The test sensitivity was $94 \%$ and specificity was $<5 \%$ cross-reactivity with TGF- $\beta 2$ and TGF- $\beta 3$ at $10 \mathrm{ng} / \mathrm{ml}$ with intra-assay and inter-assay coefficients of variations at low, medium and high concentrations of 4.5, 1.6, 3.3 and $19.1,11.6,76 \%$, respectively [16]. Peripheral venous blood samples were obtained from patients with EDTA as an anticoagulant and were centrifuged at $1,000 \mathrm{~g}$ for $30 \mathrm{~min}$. The plasma was isolated and stored at $-70^{\circ} \mathrm{C}$ until the assay was performed. To activate latent TGF- $\beta 1$ into immunoreactive TGF- $\beta 1$ detectable by the immunoassay test, we performed an acidification $(0.1 \mathrm{ml} 2.5 \mathrm{~N}$ acetic acid/10 $\mathrm{M}$ urea was added to a $0.1-\mathrm{ml} \mathrm{sample)} \mathrm{and} \mathrm{neutralization} \mathrm{(adding} 0.1 \mathrm{ml}$ $2.7 N \mathrm{NaOH} / 1 M$ HEPES) procedure (pH 7.2-7.6). Three sample dilutions $(1: 12,1: 24$, and 1:48) with calibrator diluent RD6M were performed. TGF- $\beta 1$ was determined using a solid-phase TGF- $\beta 1$ specific sandwich enzyme-linked immunosorbant assay. A TGF- $\beta 1$ standard curve was constructed using 2,000, 1,000, 500, 250, 62.5, and $31.25 \mathrm{pg} / \mathrm{ml}$ of recombinant human TGF- $\beta 1$ protein. The minimum detectable level of TGF- $\beta 1$ with the test was $7 \mathrm{pg} / \mathrm{ml}$.

Histopathological assessment was done by graft biopsy before the start of the study and at the end point. Three cores were taken in each biopsy. The cores were examined by hematoxylin and eosin and Masson trichrome stains. The extent of transplant glomerulopathy, interstitial fibrosis, tubular atrophy, arteriosclerosis, and arteriolar hyalinosis was scored as recommended by the panel members at 3rd Banff classification. A total CAN score was calculated in each case by summing up the glomerulopathy, interstitial fibrosis, tubular atrophy, arteriosclerosis, and arteriolar hyalinosis scores. Interstitial fibrosis was scored as 1 (no), 2 (mild), and 3 (moderate to severe). 
Table 1. Demographic characteristics of the treatment groups

Table 2. Baseline characteristics of the treatment groups

\begin{tabular}{|c|c|c|c|c|}
\hline Patient characteristics & $\begin{array}{l}\text { Group I } \\
(\mathrm{n}=54)\end{array}$ & $\begin{array}{l}\text { Group II } \\
(\mathrm{n}=54)\end{array}$ & $\begin{array}{l}\text { Group III } \\
(\mathrm{n}=54)\end{array}$ & $\mathrm{p}$ \\
\hline \multicolumn{5}{|l|}{ Age, years ${ }^{1}$} \\
\hline Recipients & $29.9 \pm 8$ & $31.4 \pm 8$ & $28.6 \pm 7$ & 0.2 \\
\hline Donors & $38.8 \pm 9$ & $35.4 \pm 10$ & $38.0 \pm 10$ & 0.2 \\
\hline Male recipients & 42 & 37 & 32 & 0.4 \\
\hline \multicolumn{5}{|l|}{ Causes of ESRD } \\
\hline Glomerular & 9 & 8 & 7 & \multirow{3}{*}{0.2} \\
\hline Tubulointerstitial & 11 & 13 & 12 & \\
\hline Others, unknown & 34 & 32 & 29 & \\
\hline \multicolumn{5}{|l|}{ 0-6 HLA mismatches } \\
\hline $0 / 1 / 2 / 3 / 4 / 5$ & $5 / 1 / 6 / 28 / 6 / 6$ & $2 / 2 / 9 / 22 / 9 / 7$ & $2 /-/ 5 / 24 / 7 / 5$ & 0.8 \\
\hline Retransplantation & 3 & 2 & - & 0.3 \\
\hline Donor source (related) & 49 & 46 & 43 & 0.2 \\
\hline Antihypertensives at Tx & 39 & 32 & 30 & 0.3 \\
\hline Ischemia time, $\min ^{1}$ & $39 \pm 12.8$ & $42 \pm 28.0$ & $41 \pm 8.7$ & 0.3 \\
\hline Duration before study entry, months ${ }^{1}$ & $40 \pm 29$ & $42 \pm 28.0$ & $35 \pm 34$ & 0.6 \\
\hline Acute rejection before study entry & 28 & 23 & 17 & 0.2 \\
\hline
\end{tabular}

\begin{tabular}{lcccc}
\hline Characteristics & $\begin{array}{c}\text { Group I } \\
(\mathrm{n}=54)\end{array}$ & $\begin{array}{l}\text { Group II } \\
(\mathrm{n}=54)\end{array}$ & $\begin{array}{l}\text { Group III } \\
(\mathrm{n}=54)\end{array}$ & $\mathrm{p}$ \\
\hline Blood pressure, mm Hg & $108 \pm 5$ & $106 \pm 6$ & $108 \pm 8$ & 0.5 \\
TGF- $\beta 1$, plasma level, ng/ml & $41.5 \pm 38.2$ & $39.6 \pm 25.7$ & $32.3 \pm 19$ & 0.43 \\
Serum creatinine, mg/dl & $1.5 \pm 0.4$ & $1.5 \pm 0.3$ & $1.4 \pm 0.5$ & 0.74 \\
Hemoglobin, g/dl & $12.8 \pm 2$ & $12.3 \pm 1.9$ & $12.4 \pm 1.9$ & 0.32 \\
Hematocrit, \% & $38.8 \pm 5.9$ & $37.2 \pm 5.2$ & $37.4 \pm 5.9$ & 0.28 \\
Proteinuria, g/day & $0.8 \pm 0.8$ & $0.9 \pm 0.7$ & $0.6 \pm 0.5$ & 0.14 \\
Serum potassium, mEq/l & $4.1 \pm 0.6$ & $4.1 \pm 0.6$ & $4.0 \pm 0.5$ & 0.75 \\
Serum sodium, mEq/l & $136 \pm 1.4$ & $136 \pm 106$ & $136 \pm 1.3$ & 0.35 \\
Serum uric acid, mg/dl & $5.9 \pm 1.3$ & $5.7 \pm 1.5$ & $5.9 \pm 1.3$ & 0.76 \\
CsA dose, mg/day & $155 \pm 50$ & $162 \pm 43$ & $158 \pm 39$ & 0.7 \\
CsA level, ng/ml & $128 \pm 16$ & $126 \pm 14$ & $128 \pm 9$ & 0.7 \\
Histopathological interstitial score, \% & & & & \\
$\quad$ Zero & 61 & 69 & 79 & 0.21 \\
$\quad$ One & 33 & 29 & 21 & \\
$\quad$ T Two & 6 & 2 & 0 & \\
\hline
\end{tabular}

Unless otherwise indicated, all values are means \pm SD.

\section{Statistical Analysis}

Statistical analysis was done using SPSS package version 10 . Treatment groups were compared using one-way ANOVA for continuous variables and Chi-square analysis for categorical variables. A period sample $t$ test was used to study the effect of treatment before and at the end of the study in each group. Values of $p<0.05$ were considered statistically significant.

\section{Results}

Patient characteristics are summarized in table 1. Baseline demographics were similar between the groups (table 2). Patients were studied at a mean of $39.1 \pm 30.5$ (range 1-12) months after transplantation. Six patients in group III did not complete the study because they stopped all antihypertensive drugs. 
Table 3. Changes in the mean parameters by week in the treatment groups (mean \pm SD)

\begin{tabular}{|c|c|c|c|c|c|c|}
\hline Parameters & Baseline & 1 week & 4 weeks & 12 weeks & 12 months & $\begin{array}{l}\text { Basal and } \\
12 \text { months, } p\end{array}$ \\
\hline \multicolumn{7}{|l|}{ Group I } \\
\hline Number of antihypertensives & $1.4 \pm 0.5$ & $1.8 \pm 0.7$ & $1.8 \pm 0.7$ & $1.7 \pm 0.7$ & $1.8 \pm 0.7$ & 0.001 \\
\hline Serum creatinine, $\mathrm{mg} / \mathrm{dl}$ & $1.5 \pm 0.4$ & $1.4 \pm 0.4$ & $1.5 \pm 0.5$ & $1.4 \pm 0.5$ & $1.5 \pm 0.5$ & 0.07 \\
\hline Hemoglobin, g/dl & $12.8 \pm 2$ & $12.7 \pm 1.9$ & $12.4 \pm 1.9$ & $12.2 \pm 1.9$ & $12 \pm 2$ & 0.49 \\
\hline Proteinuria, g/day & $0.8 \pm 0.8$ & $0.7 \pm 1.3$ & $0.5 \pm 0.8$ & $0.6 \pm 0.7$ & $0.4 \pm 0.4$ & 0.00 \\
\hline TGF- $\beta 1, \mathrm{ng} / \mathrm{ml}$ & $41.5 \pm 38.2$ & $27.9 \pm 19.6$ & $27.8 \pm 25$ & $18.2 \pm 16$ & $16.8 \pm 16.7$ & 0.01 \\
\hline CsA dose, mg/day & $155 \pm 50$ & $161 \pm 66$ & $157 \pm 66$ & $155 \pm 60$ & $147 \pm 54$ & 0.26 \\
\hline CsA level, ng/ml & $128 \pm 16$ & $136 \pm 32$ & $131 \pm 26$ & $124 \pm 26$ & $124 \pm 11.2$ & 0.35 \\
\hline \multicolumn{7}{|l|}{ Group II } \\
\hline Number of antihypertensives & $1.3 \pm 0.5$ & $2.2 \pm 1.4$ & $2.1 \pm 1.1$ & $2.1 \pm 1.4$ & $1.8 \pm 0.8$ & 0.00 \\
\hline Serum creatinine, $\mathrm{mg} / \mathrm{dl}$ & $1.5 \pm 0.3$ & $1.6 \pm 0.4$ & $1.4 \pm 0.4$ & $1.4 \pm 0.4$ & $1.5 \pm 0.4$ & 0.23 \\
\hline Hemoglobin, gm/dl & $12.3 \pm 1.9$ & $12.3 \pm 4$ & $12.2 \pm 3.6$ & $11.9 \pm 2.5$ & $11.4 \pm 1.4$ & 0.01 \\
\hline Proteinuria, g/day & $0.9 \pm 0.7$ & $0.8 \pm 0.6$ & $0.9 \pm 0.7$ & $0.5 \pm 0.4$ & $0.5 \pm 0.4$ & 0.001 \\
\hline TGF- $\beta 1, \mathrm{ng} / \mathrm{ml}$ & $39.6 \pm 25.7$ & $27.5 \pm 23$ & $29.7 \pm 13.5$ & $26.1 \pm 10.1$ & $31.9 \pm 8.9$ & 0.86 \\
\hline CsA dose, $\mathrm{mg} /$ day & $162 \pm 43$ & $161 \pm 58$ & $157 \pm 58$ & $155 \pm 59$ & $154 \pm 29$ & 0.2 \\
\hline CsA level, ng/ml & $126 \pm 14$ & $136 \pm 33$ & $131 \pm 23$ & $125 \pm 15$ & $122 \pm 13.5$ & 0.3 \\
\hline \multicolumn{7}{|l|}{ Group III } \\
\hline Number of antihypertensives & $1.4 \pm 0.5$ & $1.4 \pm 0.6$ & $1.4 \pm 0.6$ & $1.5 \pm 0.6$ & $1.4 \pm 0.6$ & 0.54 \\
\hline Serum creatinine, $\mathrm{mg} / \mathrm{dl}$ & $1.4 \pm 0.5$ & $1.4 \pm 0.5$ & $1.4 \pm 0.5$ & $1.5 \pm 0.5$ & $1.5 \pm 0.5$ & 0.28 \\
\hline Hemoglobin, gm/dl & $12.4 \pm 1.9$ & $12.0 \pm 1.9$ & $12.1 \pm 1.9$ & $12.2 \pm 1.9$ & $12.2 \pm 2$ & 0.57 \\
\hline Proteinuria, g/day & $0.6 \pm 0.5$ & $0.5 \pm 0.5$ & $0.9 \pm 1.0$ & $0.9 \pm 0.9$ & $0.8 \pm 0.7$ & 0.13 \\
\hline TGF- $\beta 1, \mathrm{ng} / \mathrm{ml}$ & $32.3 \pm 19$ & $33.1 \pm 34.5$ & $33.3 \pm 28.5$ & $36 \pm 29.1$ & $35.1 \pm 21.6$ & 0.24 \\
\hline CsA dose, mg/day & $158 \pm 39$ & $166 \pm 55$ & $161 \pm 52$ & $153 \pm 51$ & $149 \pm 50$ & 0.33 \\
\hline CsA level, ng/ml & $128 \pm 9$ & $131 \pm 26$ & $125 \pm 23$ & $127 \pm 22$ & $125 \pm 7.6$ & 0.11 \\
\hline
\end{tabular}

The control of blood pressure was good in all treatment groups. Statistically significant differences from baseline were observed in all treatment groups: from baseline the mean blood pressure was $108.1 \pm 5$ to $95 \pm 4$ with ARB $(\mathrm{p}<0.0005)$; from $106 \pm 6$ to $94 \pm 7 \mathrm{~mm} \mathrm{Hg}$ with ACEI $(\mathrm{p}<0.0001)$, and from $107.9 \pm 8$ to $96 \pm 10 \mathrm{~mm} \mathrm{Hg}$ with $\mathrm{CCB}(\mathrm{p}<0.0005)$. No significant differences with regard to the control of blood pressure was observed between the treatment groups $(p=0.12)$. The mean number of antihypertensives at the end of the study drugs was statistically significantly higher $(\mathrm{p}=0.03)$ in groups I and II as shown in table 3.

During the study period, no significant changes in the biochemical parameters (serum sodium and serum potassium) were observed between the treatment groups. Serum creatinine tended to increase slightly during the study period in group I (mean $\pm \mathrm{SD}, 1.5 \pm 0.4$ to $1.5 \pm$ $0.5 \mathrm{mg} / \mathrm{dl}$ ), but this change was statistically insignificant $(p=0.07)$. Serum uric acid decreased significantly in group $\mathrm{I}(\mathrm{p}=0.00)$ as shown in table 4 .
There was a significant change in the histopathological scoring of interstitial fibrosis in graft biopsy between the treatment groups $(p=0.03)$, as illustrated in table 4 . There was a significant increase from baseline score 3 in groups I, II and III (6, 2 and $0 \%$ to 12,19 and $22 \%$, respectively).

There was a significant decrease in proteinuria between baseline and at the end of the study in groups I and II $(p<0.05)$, while this effect was not significant in group III ( $p>0.05)$. There was a statistically significant difference with regard to the control of proteinuria between the treatment groups at the end of the follow-up observation period $(\mathrm{p}=0.04)$.

There was no significant difference $(\mathrm{p}=0.5)$ regarding the number of acute rejection episodes/patients during the follow-up period $(1.2,1.2$ and 1.3) in groups I, II and III, respectively.

No significant changes in the hemoglobin concentration were observed between the treatment groups $(p=0.4)$ as shown in table 4; however, there was a significant drop in hemoglobin in group II between the baseline and the end of the study $(\mathrm{p}=0.01)$ as shown in table 3 . 
Table 4. Effect of treatment on blood pressure, renal function, biochemical parameters and histopathological score at the end of the study

\begin{tabular}{lcccc}
\hline Parameters & $\begin{array}{c}\text { Group I } \\
(\mathrm{n}=54)\end{array}$ & $\begin{array}{l}\text { Group II } \\
(\mathrm{n}=54)\end{array}$ & $\begin{array}{l}\text { Group III } \\
(\mathrm{n}=48)\end{array}$ & $\mathrm{p}$ \\
\hline Blood pressure, $\mathrm{mm} \mathrm{Hg}$ & $95 \pm 9$ & $94 \pm 7$ & $95 \pm 10$ & 0.6 \\
Serum creatinine, $\mathrm{mg} / \mathrm{dl}$ & $1.5 \pm 0.5$ & $1.5 \pm 0.4$ & $1.5 \pm 0.5$ & 0.84 \\
Serum uric acid, mg/dl & $4.8 \pm 0.9$ & $5.6 \pm 1.2$ & $5.8 \pm 1.1$ & 0.00 \\
Serum sodium, mg/dl & $136 \pm 1.3$ & $136 \pm 1.4$ & $137 \pm 1.6$ & 0.12 \\
Serum potassium, mg/dl & $4.3 \pm 0.6$ & $4.3 \pm 0.6$ & $4.2 \pm 0.5$ & 0.54 \\
Hemoglobin, g/dl & $12 \pm 2$ & $11.9 \pm 1.9$ & $12.2 \pm 2$ & 0.4 \\
Hematocrit, \% & 35 & 35 & 36 & 0.3 \\
Proteinuria, g/day & $0.41 \pm 0.47$ & $0.53 \pm 0.37$ & $0.76 \pm 0.69$ & 0.04 \\
CsA dose, mg/day & $147 \pm 54$ & $154 \pm 29$ & $149 \pm 50$ & 0.75 \\
CsA level, ng/ml & $124 \pm 11.2$ & $122 \pm 13.5$ & $125 \pm 7.6$ & 0.67 \\
Plasma TGF- $\beta 1, \mathrm{ng} / \mathrm{ml}$ & $16.8 \pm 16.7$ & $31.9 \pm 8.9$ & $35.1 \pm 21.6$ & 0.001 \\
\hline Histopathological interstitial score, $\%$ & & & & \\
$\quad$ Zero & 57 & 56 & 56 & \\
One & 28 & 24 & 19 & 0.03 \\
$\quad$ Two & 11 & 17 & 19 & \\
\hline
\end{tabular}

Unless otherwise indicated, all values are means \pm SD.
TGF- $\beta 1$ serum levels decreased progressively in group $\mathrm{I}$, and the mean plasma level decreased from baseline 41.5 \pm 38.2 to $16.8 \pm 16.7 \mathrm{ng} / \mathrm{ml}$. At the end of the study, the reduction in TGF- $\beta 1$ from baseline in group I was nearly $60 \%$ which was statistically significantly different from the other groups $(p=0.001)$. In group II, TGF- $\beta 1$ plasma levels tended to decrease in the first 12 weeks, but this was not statistically significant $(\mathrm{p}=0.86)$. While it was not statistically significantly increased in group III $(p=0.11)$ as shown in table 3.

CsA doses and the whole blood trough level did not change significantly during the study period in all treatment groups as shown in table 3 .

None of the patients dropped out of the study because of adverse drug effects.

\section{Discussion}

Hypertension, together with proteinuria, is probably one of the major factors contributing to progression of $\mathrm{CAN}$, and it is also a significant determination of morbidity and mortality among kidney transplant patients. The intrarenal renin-angiotensin system has been strongly implicated in the progression of renal injury. The interaction between AngII and TGF- $\beta 1$ is worth special emphasis. In various models, AngII inhibition has ameliorated the pathologic changes associated with the upregulation of
TGF- $\beta 1$ [16]. Although increased TGF- $\beta 1$ expression can induce collagen synthesis by itself and may mediate tissue scarring directly, whether or not AngII acts as an immune costimulator in the regulation of the immune response remains a matter of debate. In different animal models, the ARBs and ACEIs have been proven to limit proteinuria and to decrease glomerulosclerosis and improve graft survival $[17,18]$.

Josep et al. [19] have suggested that a decrease in TGF$\beta 1$ and ET-1 levels may play an important role in protecting against progression toward CAN. In the present study, we demonstrated that despite similar control of blood pressure with therapeutic drugs, the effects on profibrogenic cytokines were different. Contrasting effects were observed with respect to the plasma level of the profibrogenic cytokine TGF- $\beta 1$ : AngII blockers, caused a significant decrease, whereas ACEI and CCB caused no significant change. The nonsignificant decrease in TGF- $\beta 1$ plasma levels could be related to the small doses used in our study. In one study Campistol et al. [20] demonstrated that treatment with losartan significantly decreased the plasma levels of TGF- $\beta 1$ in renal transplant patients with CAN. The observed decrease in TGF- $\beta 1$ was approximately $50 \%$ from the initial levels. The same effect on TGF- $\beta 1$ plasma levels was also demonstrated with ACEI (captopril) in diabetic patients with proteinuria [21]. In the present study, we documented that the ARB losartan has a similar effect on TGF- $\beta 1$ plasma levels in renal 
transplant patients with normal function. The decrease in the TGF- $\beta 1$ plasma levels was approximately $60 \%$ from the initial level. These results confirmed the data reported by Campistol et al. [20] who reported that ARB decreased the synthesis and secretion of renal TGF- $\beta 1$ and prevented the development of interstitial fibrosis and subsequently CAN. The initial decrease in plasma TGF- $\beta 1$ levels in the captopril group was not sustained to the end of the study and may be related to the small dose used in the study.

In the present study, the control of blood pressure was good in all treatment groups without any significant differences. Hypertension was severe enough to require one or more other antihypertensive drugs in nearly 30\% of patients. To reach the target blood pressure the need for other antihypertensive drugs was significantly less in the CCB group. This finding was similar to the data reported by Van der Schaaf et al. [22]. No adverse events related to the use of our treatment drugs on immunosuppressive treatment were observed. The combination with CsA did not significantly modify the levels or the doses of CsA.

The negative impact of proteinuria in the evolution of diseases of native and transplanted kidneys is well known $[23,24]$. In this study, most of the patients in our cohort did not have significant proteinuria. However, a significant reduction or at least stabilization of urinary protein excretion was detected at the end of follow-up in the ARBs and ACEI groups. This effect was already observed after 3 months of therapy in both groups. Moreover, a new onset of proteinuria was not documented during the period on losartan in any of the non-proteinuric cases. Our results are in agreement with the report of Kim et al. [25] who described a significant reduction in the proteinuria of hypertensive renal transplant patients treated with the ACEI, enalapril, and the ANGII blocker, losartan, and the study by Martinez-Castelao et al. [26] who found more anti-proteinuric effects in patients on ACEI than those on CCBs. Furthermore, no correlation was found between the reduction in proteinuria and control of blood pressure, suggesting that the anti-proteinuric effect of losartan or captopril was independent of blood pressure changes.

Overall graft function was not influenced during the observation period in all treatment groups. No acute renal function derangement was observed after initiation of losartan or captopril; however, there was a nonsignificant increase in plasma serum creatinine over the baseline values despite the drop in urinary protein excretion in the AngII blocker and ACEI groups. Furthermore potassium levels did not change significantly, and serious hyperkalemia necessitating drug withdrawal was not documented in our series. These results confirmed what has been observed in other studies $[6,15,27]$.

In fact, the most commonly observed side effect was a decrease in hemoglobin concentration in the ACEI group. Several studies have previously documented ACEI-related anemia in patients with normal renal function, renal disease and in renal transplant recipients without polycythemia [28]. In other groups the decrease in hemoglobin levels was slight with no clinical significance.

In conclusion, the present study demonstrated that ARB (losartan), ACEI (captopril) and CCB (amlodipine) were effective in controlling hypertension in renal transplant patients with good safety and tolerability. The beneficial anti-proteinuric effect of ARBs and ACEI may afford renal protection in these patients. Analysis of the effects on the plasma levels of TGF- $\beta 1$ may suggest that ARBs could be potentially valuable in interfering with or preventing CAN. The nonsignificant decrease in plasma TGF- $\beta 1$ levels in the captopril group may be related to the small dose used in the study.

\section{References}

1 Curtis JJ: Cyclosporine and post-transplant hypertension J Am Soc Nephrol 1992;2:S243S245.

2 Luke RG: Pathophysiology and treatment of post-transplant hypertension. J Am Soc Nephrol 1991;2:S37-S44.

3 Opelz G, Wujciak T, Ritz E: Association of chronic graft failure with recipient blood pressure. Collaborative Transplant Study. Kidney Int 1998:53:217-222.

Angiotensin II Receptor Blocker Could

Prevent Progression of Chronic Allograft Nephropathy
4 Inigo P, Campistol JM, Lario S, Piera C, Campos B, Bescos M, Oppenheimer F, Rivera F: Effects of losartan and amlodipine on intrarenal hemodynamics and TGF-beta(1) plasma levels in a crossover trial in renal transplant recipients. J Am Soc Nephrol 2001;12:822827.

5 Bochicchio T, Sandoval G, Ron O, PerezGrovas H, Bordes J, Herrara-Acosta J: Lisinopril prevents hyperfiltration and decreases proteinuria in post-transplant hypertensives. Kidney Int 1990;38:873-879.
6 Stigant CE, Cohen J, Vivera M, Zaitzman JS: ACE inhibitors and angiotensin II antagonists in renal transplantation: An analysis of safety and efficacy. Am J Kidney Dis 2000;35:5863.

7 Lee DB: Cyclosporine and the rennin-angiotensin axis. Kidney Int 1997;52:248-260.

8 Khanna A, Kapur S, Sharma V, Li B, Suthanthiran M: In vivo hyperexpression of transforming growth factor beta 1 in mice: Stimulation by cyclosporine. Transplantation 1997;63: 1037-1039. 
9 Little DM, Haynes LD, Alam T, Geraghty JG, Sollinger HW, Hullett DA: Does transforming growth factor $\beta 1$ play a role in the pathogenesis of chronic allograft rejection? Transplant Int 1999;12:393-401.

10 Woltenberges J, Miyazono K, Funa K, Wonders A, Fellstrom B, Heldin $\mathrm{CH}$ : Transforming growth factor- $\beta$ and organ transplantation. Transplant Proc 1993;25:2038-2040.

11 Suthanthiran M, Khanna A, Cukran D, Adhikarla R, Sharma VK, Singh T, August P: Transforming growth factor-beta 1 hyperexpression in African American end-stage renal disease patients. Kidney Int 1998, 53:639-644.

12 Border WA, Noble NA: Interactions of transforming growth factor-beta and angiotensin II in renal fibrosis. Hypertension 1998;31:181188.

13 Shihab FS, Tanner AM, ShaoY, Weffer MI: Expression of TGF-beta 1 and matrix proteins is elevated in rats with chronic rejection. Kidney Int 1996;50:1904-1913.

14 Amuchastegui SC, Azzollini N, Mister M, Pezzotta A, Perico N, Remuzzi G: Chronic allograft nephropathy in the rat is improved by angiotensin II receptor blockade but not by calcium channel antagonism. J Am Soc Nephro 1998;9:1948-1955.

15 Calvino J, Lens XM, Romero R, SanchezGuisande D: Long-term anti-proteinuric effect of losartan in renal transplant recipients treated for hypertension. Nephrol Dial Transplant 2000;15:82-86.
16 Anderson S, Jung FF, Ingelfinger JR: Renal renin-angiotensin system in diabetes: Functional, immunohistochemical, and molecular biological correlations. Am J Physiol 1993;265: F477-F486.

17 Benediktsson H, Chea R, Daridoff A, Paul LC: Antihypertensive drug treatment in chronic renal allograft rejection in the rat: Effect on structure and function. Transplantation 1996;62: 1634-1642.

18 Anderson S, Rennke HG, Brenner BM: Therapeutic advantage of converting enzyme inhibitors in arresting progressive renal disease associated with systemic hypertension in the rat. $\mathbf{J}$ Clin Invest 1986;7:1993-2000.

19 Josep M, Campistol I, Inigo P, Larios S, Bescos M, Oppenheimer F: Role of transforming growth factor- $\beta 1$ in the progression of chronic allograft nephropathy. Nephrol Dial Transplant 2001;16(suppl 1):114-116.

20 Campistol JM, Inigo P, Jimenez W, Lario S, Clesca PH, Oppeheimer F, Rivera F: Losartan decreases plasma levels of TGF- $\beta 1$ in transplant patients with chronic allograft nephropathy. Kidney Int 1999;56:714-719.

21 Sharma K, Eltayeb BO, Mc Gowan TA, Dunn SR, Alzahabi B, Rohde R, Ziyadeh FN, Lewis EJ: Captopril-induced reduction of serum levels of transforming growth factor beta- 1 correlates with long-term renoprotection in insulindependent diabetic patients. Am J Kidney Dis 1999;43:818-823.
22 Van der Shaaf MR, Hene RJ, Floor M, Blankestijn PJ, Koomans HA: Hypertension after renal transplantation, calcium channel or converting enzyme blockade. Hypertension 1995; 25:77-81.

23 Jafar TH, Stark PC, Sehmid CH: Proteinuria is a modifiable risk factor for the progression of non-diabetic renal disease. Kidney Int 2001; 60:1131-1140.

24 Bio MJ: Non immunologic causes of late renal graft loss. Kidney Int 1995;47:49-54.

25 Kim W, Lee S, Kang SK, Yu HG, Cho BH, Pork SK: Effects of angiotensin converting enzyme inhibitor and angiotensin II receptor antagonist therapy in hypertensive renal transplant recipients. Transplant Proc 2002;34: 3223-3224.

26 Martinez-Castelao A, Hueso M, Sanz V, Rejas $\mathrm{J}$, Alsina J, Gringo JM: Treatment of hypertension after renal transplantation: Long-term efficacy of verapamil, enalapril and doxazocin. Kidney Int 1998;68(suppl 1):S130-S134.

27 Castillo D, Campistol JM, Guiradio L, Capdevilla L, Martinez JG, Pereira P, Bravo J, Perez $R$ : Efficacy and safety of losartan in the treatment of hypertension in renal transplant recipients: results of multicenter study. Kidney Int 1998;54(suppl 68):S135-S139.

28 Vlahakas DV, Canzanello VJ, Madaio MP, Madias NE: Enalapril-associated anemia in renal transplant recipients treated for hypertension. Am J Kidney Dis 1991;17:199-205. 